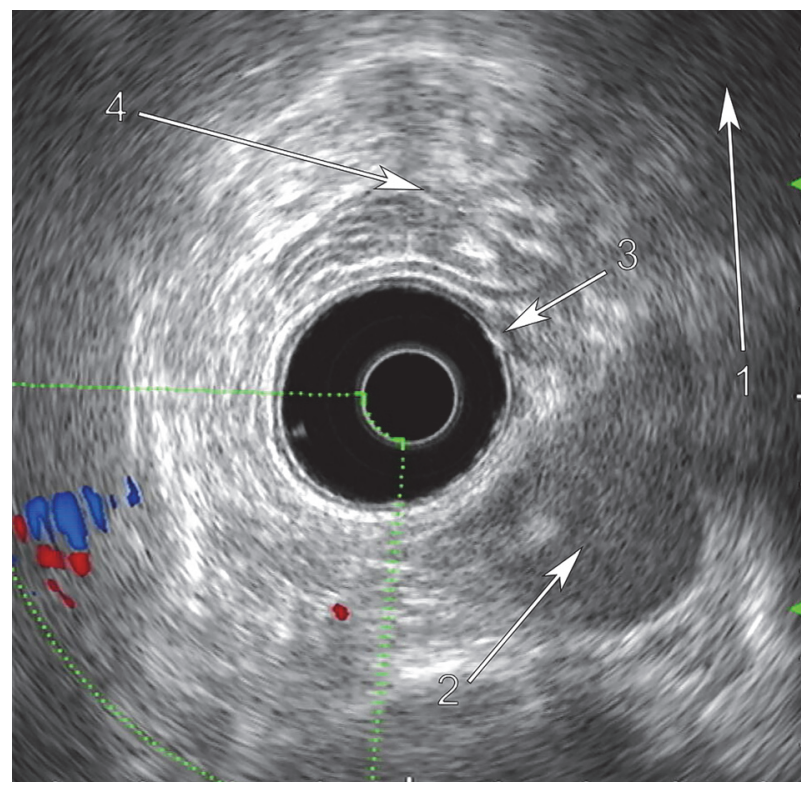

Abstract IDDF2021-ABS-0139 Figure 2

Conclusions Endoscopic ultrasonography has demonstrated high diagnostic value related to various anatomical variants of $\mathrm{HH}$. EndoUS is of the greatest importance for the verification of $\mathrm{HH}$ type I of small size.

\section{IDDF2021-ABS-0144 DENTAL INJURY DURING ENDOSCOPY: AN UNDERRECOGNIZED TEETHING SAFETY ISSUE}

${ }^{1}$ Gabrielle Loh Yi Wen*, 'Chelsea Tan Qiu Lin, 'Benjamin Tay Wei Rong, ${ }^{2} J o h n$ Mok, ${ }^{2}$ Calvin Koh Jianyi, ${ }^{2}$ Leo Juanda, ${ }^{2}$ Tien Ho Siah. ${ }^{1}$ National University of Singapore, Singapore; ${ }^{2}$ National University Hospital, Singapore

\subsection{6/gutjpl-2021-IDDF.156}

Background Dental injury is an underrecognized preventable complication during endoscopy. An audit of same-day procedure cancellation in our endoscopy center showed that $43 \%$ of cases are related to tooth safety concerns. A review of the literature showed that dental injury was under-reported in endoscopy related journals but an important issue in anaesthesia. Dental injury in anaesthesia is variably estimated to occur at a rate of approximately one in 1,000 to 4,500 . It represents up to half of all anaesthetic claims. We reviewed the preventive measures and management strategy of dental injury.

Methods We have reviewed the available literature and worked with a dental expert to suggest a few steps to improve tooth safety during endoscopy:

Results Key steps in preventive measures: 1) Pre-endoscopic tooth screening: Optimal pre-endoscopic assessment should include a comprehensive dental assessment, documentation and explanation of individualized risk involved. 2) Identification of risk factors: Evidence of periodontal disease and its infective complications, pre-existing dental pathology such as missing or loose teeth, and dental restorations. 3) Comprehensive documentation of pre-existing dental defects prior to endoscopy should be done.
Key steps in dental injury management: 1) Early involvement of dentist: If a dental injury occurs or a missing tooth is found during endoscopy, a dentist should be called to do an on-table consult. 2) Tooth retrieval whenever possible: If the dentist is unavailable or delayed, the missing tooth should be localised and retrieved. Upon retrieval of the tooth or tooth fragments, the dental officer on-call should be consulted for specific management. 3) Radiographic assistance: If localisation is not possible, a chest X-ray should be done, with the consultation of Thoracic Surgery.

Conclusions We encourage these simple measures to be implemented in the clinic and endoscopy center to prevent dental injury during endoscopy.

\section{IDDF2021-ABS-0146 PEDIATRIC COLONOSCOPY IN A TERTIARY CENTER: A 10-YEAR EXPERIENCE}

Jan Pofer Mantos*, Portia Menelia Monreal, Caroline Anne Castro. University of Santo Tomas Hospital, Philippines

\subsection{6/gutjnl-2021-IDDF.157}

Background There has been no retrospective study yet on the role of colonoscopy in children in our local setting; thus, this is the first study to review the experience of pediatric colonoscopy in the Philippines.

Methods This is a cross-sectional study through retrospective chart review with an analytical component. The study included in-patients aged 0 to 18 years old who underwent their first colonoscopy between January 1, 2010 and December 31, 2019 at the University of Santo Tomas Hospital.

Results A total of 196 respondents were included in the study with a mean age of 8.6 years, with slight male predominance $(51.5 \%)$.

Table 1. The most common indication for colonoscopy was hematochezia. Among the patients with hematochezia, 94.2\% had positive colonoscopy findings (IDDF2021-ABS-0146 Table $1)$.

Table 2. The most common findings were non-specific colitis, polyps, non-specific pancolitis, internal hemorrhoids, and ileitis (IDDF2021-ABS-0146 Table 2).

Table 3. The most common bowel preparation used were Fleet enema, Bisacodyl suppository, and Castor oil (IDDF2021-ABS-0146 Table 3).

Abstract IDDF2021-ABS-0146 Table 1 Descriptive Statistics for the Indications for Colonoscopy $(\mathrm{N}=196)$

\begin{tabular}{llll}
\hline $\begin{array}{l}\text { Indications of } \\
\text { Colonoscopy }\end{array}$ & $\begin{array}{l}\text { Frequency } \\
(f)\end{array}$ & $\begin{array}{l}\text { Percentage } \\
(\%)\end{array}$ & $\begin{array}{l}95 \% \text { Confidence Interval } \\
(\mathrm{Cl})\end{array}$ \\
\hline Hematochezia & 156 & $79.6 \%$ & $73.3 \%-84.7 \%$ \\
Constipation & 5 & $2.6 \%$ & $1.1 \%-6.0 \%$ \\
Melena & 10 & $5.1 \%$ & $2.8 \%-9.3 \%$ \\
Diarrhea & 10 & $5.0 \%$ & $2.8 \%-9.3 \%$ \\
Abdominal Pain & 12 & $6.1 \%$ & $3.5 \%-10.5 \%$ \\
Weight Loss & 1 & $0.5 \%$ & $0.1 \%-3.6 \%$ \\
Occult Bleeding & 1 & $0.5 \%$ & $0.1 \%-3.6 \%$ \\
Surveillance & 1 & $0.5 \%$ & $0.1 \%-3.6 \%$ \\
\hline
\end{tabular}

